\title{
Time Management in the Context of Elite Sport Training
}

\author{
Anne-Claire Macquet \\ Institut National du Sport, de l'Expertise et de la Performance
}

\begin{abstract}
This article reports on time management in an elite sports context. It aims at characterizing how coaches experience dealing with athletes' time management in a sport and academic institute and their constraints. Ten male coaches participated in this study. Each coach was asked to describe his time management activity during the season. Inductive and deductive analysis revealed two main results. The first showed the coaches dealt with a stringent set of constraints concerned with: (a) season organization, (b) training period and task sequencing, (c) the institute's set times, and (d) the uncertainty linked to the evolution of training. The second emphasized that the coaches used three complex operating modes: (a) the use of organizational routines based on reference to past experience, (b) season shared time management, and (c) time management based on flexible plans. The results are discussed in relation to research that has considered planning and time management.
\end{abstract}

The primary function of coaches in elite sport contexts consists of organizing athletes' work to achieve results in competitions. Some authors highlighted the importance of this work organization along time (e.g., Côté, 2006; Côté, Salmela, Trudel, Baria \& Russel, 1995; Gilbert \& Trudel, 2000; Gould, Guinan, Greenleaf $\&$ Chung, 2002). In other words, work organization is related to time organization. Côté and Sedgwick (2003) emphasized that only a few sport psychology studies have considered time organization components. In the literature, time was organized according to a rational model that aims to optimize or rather maximize the time available for work as its goal (e.g., Burton \& Raedeke, 2008; Burton \& Weiss, 2008; Gould et al., 2002; Horton \& Deakin, 2008; Weineck, 1986). Time organization was mainly concerned with planning. Planning consists of the different steps and timeframes that one thinks are required to reach a goal. Each step indicates what has to be done. Everything seems to be predicted to reach the result. Côté and Sedgwick (2003) showed that coaches prepared their athletes for unexpected situations that could have occurred during training sessions or competitions; they plan proactively.

The literature on planning largely focused on the identification of the components used by the coaches to set out plans. Planning was considered indirectly (e.g., Côté et al., 1995) or directly (e.g., Abraham, Collins \& Martindale, 2006) as a decision making process that was based on the use of knowledge. In their

\footnotetext{
Macquet is with the Institut National du Sport, de l'Expertise et de la Performance, Laboratoire de Psychologie et d'Ergonomie du Sport, Paris, France.
} 
integrated definition of coaching expertise, Côté and Gilbert (2009) described three types of coaching knowledge: professional, interpersonal and intrapersonal. According to Abraham et al. (2006), professional knowledge contained declarative and procedural knowledge concerned with the sport sciences and the pedagogy, and were sport specific. Interpersonal knowledge was continuously developed from individual and group interactions. According to Gilbert and Trudel (1999, 2005), intrapersonal knowledge was concerned with understanding of oneself and the ability for retrospection and reflection. Abraham and Collins (1998) also showed that coaches' knowledge referred to rules containing if-then statements.

Planning was based on the taking into account of many contextual variables, including athletes' parents, job conditions and assistant coaches (Côté et al., 1995; Gilbert \& Trudel, 2000). These variables were limited to individuals; they did not relate to the practice structures (i.e., training center, federations). To our knowledge, nothing seems to be reported on the constraints represented by these structures and how the coaches manage them.

Beyond the components used to set out plans, some studies focused on the operating dimensions of planning activity or on plan implementation. Jones, Housner and Kornspan (1995) centered on planning activity. They compared expert and novice coaches as they planned a short basketball training session. They showed that expert coaches used more highly organized knowledge than novices; they identified more goal constraints and goal subproblems than novices. Jones et al.'s study was limited to planning practice sessions. Some of the studies presented above and others (e.g., Salmela, 1996) focused on how coaches implemented plans and how they adapted them to on-going events. Two sorts of plan adaptations had been considered: adaptations over a season and adaptations over a training session. Coaches in elite sport contexts adapted plans when they faced unanticipated problems concerned with conflicts between time dedicated to sport and academics or a job (Côté et al., 1995; Gilbert \& Trudel, 2000; Salmela, 1996). Gilbert and Trudel (2000) emphasized a coach tendency to manage personal development and sports development at the same time. These studies showed the constraints the coaches managed when they adapted plans but they did not account for the coaches' adaptive activity.

Saury and Durand (1998) and Sève and Durand (1999) studied the coaches' adaptive activity in the course of a training session. Saury and Durand (1998) showed that to manage constraints, coaches used various operating modes including the use of routines, flexible planning strategies, joint control of training with athletes and reference to past experiences. These two studies showed that the coaches' actions were grounded on different intermixed temporalities that referred to past experiences, current situations and what was expected of the athletes. However, these studies were limited to short time-frames.

Coaching activity, including time organization and planning, appears to be dynamic and chaotic (Bowes \& Jones, 2006). It is generated by on-going events. It comprises endless dilemmas and decision-making and requires constant planning, observation and evaluation; it cannot be explained according to a linear and rationalistic approach (Bowes \& Jones, 2006; Cushion, Armour \& Jones, 2003; Jones, 2000; Jones \& Wallace, 2005; Potrac, Brewer, Jones, Armour \&Hoff, 2000; Potrac \& Jones, 1999). Coaches constantly have to manage with constraints. The studies presented above showed the process used to set out plans (set apart those 
of Saury \& Durand, 1998; Sève \& Durand, 1999) and the constraints the coaches had to manage when they implemented plans. The studies did not account for the adaptive activity of the coaches when they managed constraints over a season. They also did not show how coaches managed different athletes' time, including time for sports training and time for out-of-training activities in a sport structure where athletes are committed to both sports and academic programs within sports institutes and universities (e.g., Bouchetal-Pellegri, Leseur, \& Debois, 2006). Côté and Sedgwick (2003) suggested that more research on sports organization was necessary. Gould et al. (2002) highlighted the need to understand the psychological principles used by experienced coaches and the principles they considered as efficient to help less experienced coaches. They also emphasized the need to take a more multidisciplinary approach to study the performance process.

Performance process within time organization has been studied in sociology, psychology and management sciences within the concept of time management. Grossin (1996) and Francis-Smythe and Robertson (1999) showed that managers' time was fragmented, multiple and non linear. Managers had to master fluid and flexible temporal systems and were required to be flexible. Sabelis (2001) highlighted the need to investigate the interwoven layers of other temporal traits and aspects. She underlined the interest of reconstructing the process by which time is managed in theory, through training programs and the experience of people 'managing their time'.

In addition to explaining how to manage risky and unavoidable situations and going beyond the simple risk theory, Dupuy $(2002,2008)$ has developed a metaphysics of temporality. He presented a model of time management called time of project. This consists of a loop between the past and the future. The future refers to the expectations of events one wants to avoid (e.g., a catastrophe) or to happen (e.g., medals to be won by athletes in major competitions). The future is anticipated and is considered to be already realized. This anticipation becomes the fixed point of the loop. It is from this fixed point that 'the predictor' investigates the 'past' (i.e., a past which is not yet realized). The 'predictor' knows that his/her prediction is going to produce some causal effects in the world (e.g., preparation for competitions). He/she takes them into account to realize or avoid the predicted future. Time of project is looped: future and 'past' are thus codetermined. It appears in the same way as a retrospective causal relation model. In the course of time, the agents adjust themselves to the emerging structural, factual and human constraints to achieve the causal production of the future. Time management refers to this process consisting of anticipating a result at a specific moment, setting timeframes regarding constraints and adjusting them in the course of time to achieve the anticipated result. Time of project model identifies the constant adjustment of flexible plans to achieve a specific result and describes what can be observed when expert coaches manage time in training activities. It provides theoretical and practical insights about time management in sports training activities. It allows for the reduction in tensions linked to the uncertainty of practice, by not trying to predict what is unpredictable but rather by fitting reality into the practice. Previous studies showed the components used to set out plans (e.g., Côté \& Sedgwick, 2003), the coaches' operating modes during planning (Jones et al., 1995) or adaptive activity during training sessions (Saury \& Durand, 1998). The time of project model could extend knowledge about coaches' time management activity over a season. 
The present article aims at characterizing how coaches manage athletes' time in elite sport settings. More specifically, it aims at characterizing the constraints the coaches have to deal with in managing athletes' time and the coaches' activity when they experience time management in an elite sport and academic training institute.

\section{Method}

\section{Participants}

Coaches of elite athletes were selected to participate in the study. The criteria employed to select them included: (a) being head coach, (b) coaching in the same institute for sport and academic training, (c) a minimum of 10 years' coaching experience in elite sport, (d) development of several international level athletes, and (e) recognition for outstanding coaching (i.e., considered by their federation as one of the best coaches in France). Ten coaches were selected and agreed to participate in the study. Data saturation was reached after reviewing interviews from the 10 coaches. Coaches ranged in age from 36 to 59 years $(M=47$ years, $S D=7$ years and 10 months). Nine of them were elite athletes before coaches. They all had French coaching qualifications. They were all male. No female coach fulfilled all these requirements and was available to participate in the interview. This gender exclusivity reflects a gender equity problem in coaching in France; there are very few female coaches of elite athletes in Olympic sports (Lamberbourg \& Paudardin, 2008). Dubar and Tripier (2005) explained the gender difference through the concept of the glass ceiling. This ceiling significantly limits female access to positions of power and domination in professional groups. The coaches covered nine Olympic sports: combat, individual and team sports; they referred to different competition calendars. They coached the following sports at the same institute for sport and academic training: fencing, wrestling, judo, cycling, gymnastics, swimming, athletics $(n=2)$, badminton, and basketball. This institute has agreements with universities, middle and high-schools, companies, and sport federations. It allows athletes at the same time and place to prepare for elite sport competition and to pursue their studies or to work (while some of them work nearby). Most athletes live in the institute. All the coaches were recruited through personal contact by a member of the research team. They were informed of the purposes of the study and assured of anonymity.

\section{Data Collection}

An interview was conducted with each coach. It lasted between 75 and $90 \mathrm{~min}$. The coaches were asked to comment on their diary or planning sheets and to describe the concomitant time organization activity. These documents showed evidence of some of their activity. They were used as a starting point. The coach was asked to describe and comment on his time-frames and plans and how he set them (Jeannot, 2000). The recalling of a specific time or time-frame was followed by comments about the meaning, origin, and carrying through of a particular task. The followsup were concerned with: (a) the international and national sport calendars (e.g., "what events do you take into account first?"), (b) the work orientation for each period (e.g., "what do you do at the beginning of this period?”), (c) the moments 
for collective or individual work with athletes (e.g., "Is this planning concerned with all the athletes on the team?"), (d) the adjustments in the course of time (e.g., "do you carry out everything that you have envisaged?") and (e) the time-frames imposed by the training center (e.g., "How do you manage time when you take into account different athletes' activities?”).

\section{Data Processing}

Interviews were transcribed verbatim and given to the participants to confirm the validity of transcription. Data processing was done using the constant comparative method (Corbin \& Strauss, 1990). Interview transcripts were divided into 1230 meaning units considered by the coaches and the related constraints. The properties of these meaning units were compared and classified into 28 categories according to their common features. Each category was labeled and their properties defined. As the data analysis proceeded, two other levels of interpretation emerged from a comparison between properties of categories (see Table 1). Two researchers analyzed the verbal reports separately. The data were constantly compared until saturation was reached, which occurred when no more new categories emerged from the data. The results were given to the participants. They were requested to read them and to indicate whether they felt that the results accurately reflected their time management. They agreed with the results.

\section{Results}

The results are presented in two parts in relation to the time of project model. The first deals with the circular process and more specifically the constraints the coaches manage to achieve the anticipated result. The second refers to the cognitive activity the coaches used when they managed these constraints to achieve the anticipated result. These parts are linked together and indicate a holistic view of time management. These results are illustrated by excerpts from the interview transcripts.

\section{Anticipated Result and Constraints of Time Management}

To manage time in the current complex, dynamic and constrained world of sports management and organization, the coaches anticipated a specific result in major competitions or a work time span. This anticipation led them to set time-frames according to the constraints and to adjust them to the on-going-events to achieve the anticipated result. For example a coach said:

"My aim for the athletes is to be in shape for the competitions. To do that, I organize the season into important moments, different cycles... In practice, I have to fit everything in between the dates of the major competitions, the mode of selection [...] Then, I adapt cycles and training sessions according to the athletes' progress [...].

Coaches dealt with a stringent set of constraints to manage time in order to achieve the anticipated result. This set of constraints was related to: (a) season organization depending on the fit between the anticipated result for the athletes and times for 


\section{Table 1 Results of Qualitative Analysis of Interviews Displaying Hierarchical Categories}

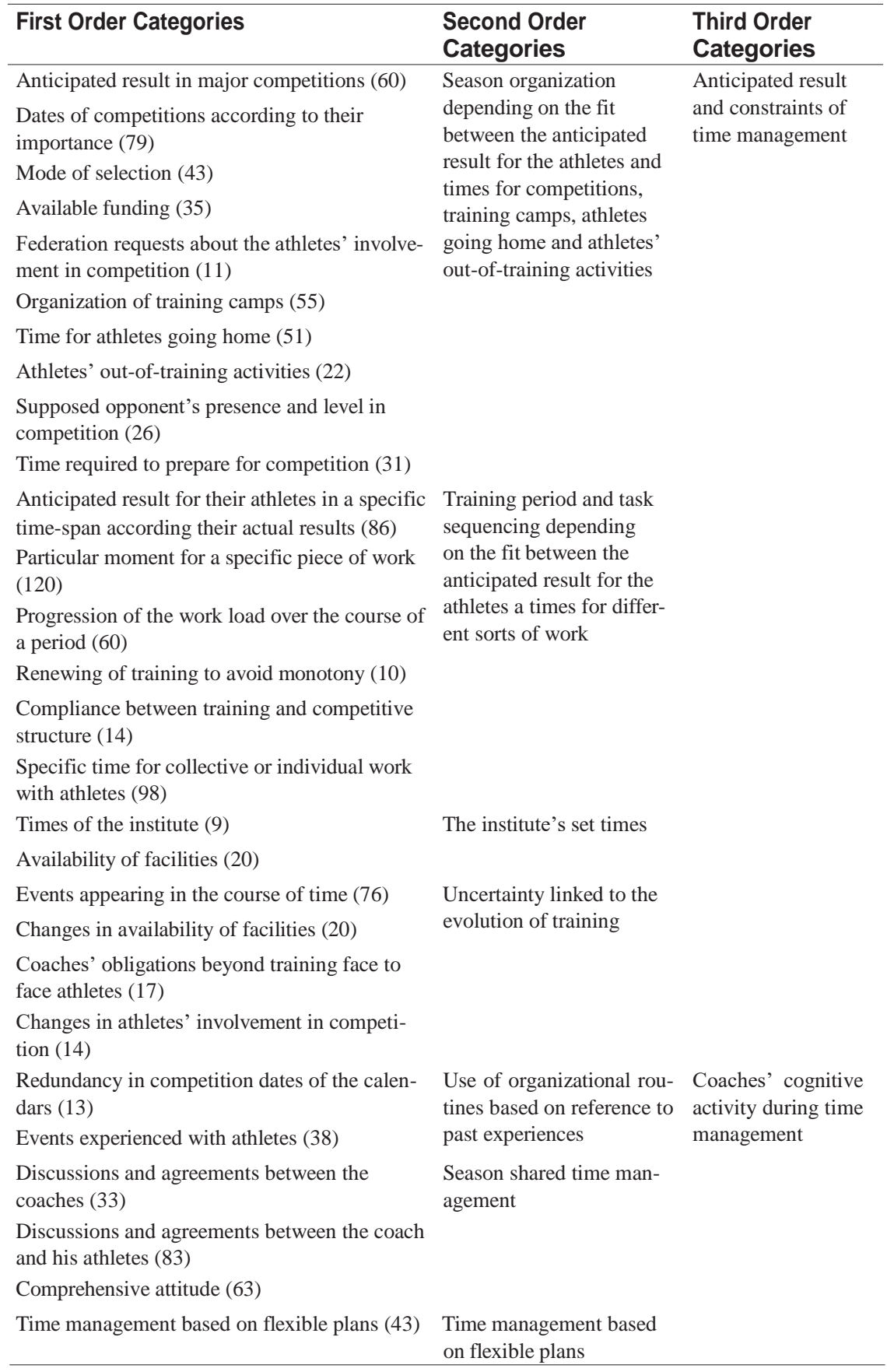

Note. Numbers in brackets displays how many occurrences contributed to the raw data. 
competitions, training camps, athletes going home and athletes' out-of-training activities (b) training period and task sequencing depending on the fit between the anticipated result for the athletes and time for different sorts of work, (d) the institute's set times, and (e) uncertainty linked to the evolution of training.

\section{Season Organization Depending on the Fit Between the Anticipated Result for the Athletes and Times for Competitions, Training Camps, Athletes Going Home and Athletes' Out-of-Training Activities. Coaches managed time during the season to organize times for competitions, training camps, athletes going home and athletes' out of training activities. They set a season calendar for their athletes fitting in these stringent constraints to achieve the anticipated result. For example a coach said:}

"With these top athletes we aim to win medals. To do so, it's up to us to determine a calendar from the international calendar, in order to combine a coherent planning for sport training with academic studies for younger athletes, and sport training with a job for older ones, coherent planning that brings them to the more important competitions in the best possible conditions."

In the same way as this coach mentioned, all the coaches anticipated a result (e.g., "winning medals") and then managed constraints linked to the structures, the athletes and the training process. These constraints were concerned with: (a) the dates of competition according to their importance (e.g., "The Continental Championships are in April". The World Championships are at the end of September"), (b) the mode of selection for these competitions (e.g., "the National Championship is selective for the Continental Championship"), (c) the available funding (e.g., "If we don't obtain the funding we've expected, we've to reduce traveling"), (d) the national federation requests for the athletes' involvement in competitions (e.g., "We free up the athletes for the Inter-club Championship"), (e) the organization of training camps (e.g., "When I've some time, I try to organize a training camp to get out of the usual training center"), (f) time for athletes going home (e.g., "Each time, I try to give them time to go home. They need to go home"), (g) their out-of-training activities (e.g., "we have to free them up for their studies or their job"), (h) the supposed opponents' presence and level in competition (e.g., "I try to choose the competitions where I'm sure that there will be many opponents"), and (i) time required to prepare for competitions (e.g., "I need a minimum of four weeks between two important competitions"). In managing these constraints, the coaches organized time spans for competitions, training camps, athletes going home and their out of training activities. The coaches most frequently reported constraints from the dates of competitions impacting upon achievement of the anticipated result (see Figure 1). They did not frequently comment on the national federation requests.

Training Period and Task Sequencing Depending on the Fit Between the Anticipated Result for the Athletes and Time for Different Sorts of Work. Time organization efficiency was not only a function of a succession of time-frames for a specific work, it also concerned the way the tasks or time-frames were chained together into a temporal sequence. To sequence tasks and periods, coaches anticipated a specific result for their athletes in a time span according to their actual results. For example a coach said: 
"We plan a period with each athlete, taking into account his/her results during the last competition or during the last six week period [. . .]. We expected her to reach her optimal form through particular educative drills, at the end of November. We began the period using specific educative drills, using two rotations. We increased the weight of the hammer and the number of repetitions. To avoid the monotony of an annual planning sheet, consisting of doing the same things at the same periods, we change the implement weight, the wire length [. ..] We sequence training days according to the competitive structure. Athletes train on two consecutive days and have one day off, because competitions are organized over two consecutive days: qualifications and the final."

In this excerpt and in the other coaches' data, the sequencing was ruled by different elements: (a) particular moment for a specific piece of work (e.g., "two rotations at the beginning of the period"), (b) progression of the work load over the course of the period (e.g., "increase the weight of the hammer"), (c), the renewing of training to avoid monotony (e.g., "we change the implement weight"), (d) the compliance between training and competitive structure, and (e) specific times for collective or individual work with athletes. Regarding compliance, competitions are organized according to a specific structure, depending on the sport. Preparing for competitions required the coaches to take this organization into account to allow their athletes to become accustomed to performing in such a temporal structure. In relation to specific times for collective and individual work with athletes, a coach reported:

"during March and April, everybody does the same work. In May and June, we're in a competitive period and we take them case by case and day by day."

This organization went from a collective form when they were distant from competition times to an individual form when they were during or just before the competitive period. The coaches most frequently reported elements concerned with a particular moment for a specific work (see Figure 1). They reported elements linked to the renewing of training to avoid monotony less frequently.

The institute's set times. Coaches worked within an institute that organized schedules for sports and academic training. The coaches adjusted their training times to these schedules and to the availability of facilities For example a coach said:

"Organization depends on academic constraints. I'd prefer they swim at eight, but it isn't possible here, they have to swim after ten."

The coach had to fit in his training schedules around the institute schedules. Coaches also managed the availability of the facilities according to the number of athletes. For example a coach said:

"The first thing that I take into account is the space. We've got a gym for 24 players; we've got two central baskets. We divide the group into two groups of different levels. One group trains in the central area and the second trains on the sidelines. Then we change. We have to adapt the training session to the space; all the players come for training at the same time. Before that, they pursue academic studies ..." 
This coach organized the athletes' training sessions according to the available space and the schedules of the institute to allow each athlete to train in the best possible conditions.

Uncertainty Linked to the Evolution of Training. This type of constraint was generated by the uncertainty linked to the evolution of training with regard to athletes' activity and changes in the constraints. This uncertainty depended on: (a) events appearing in the course of time such as injuries or a decrease in performance (e.g., "we were involved in a training camp 15 days before the World Championship, this athlete was completely lost, he could not put one foot in front of the other anymore"), (b) changes in the availability of facilities (e.g., "Sometimes the pool is occupied for exams, they only have half a pool to swim in"), (c) coaches' obligations beyond training (e.g., "When I've a meeting, I free them"), and (d) changes in an athlete's involvement in a competition (e.g., "When we were in China, we noticed that she wasn't on the Taiwan table. They forgot to register her."). Uncertainty led the coaches to adjust their plans according to the constraints that appeared in the course of time. The coaches reported more frequently on events appearing in the course of time than changes in an athlete's involvement in a competition (see Figure 1).

\section{Coaches' Cognitive Activity During Time Management}

To deal with these constraints, the coaches used complex operating modes. Three modes were identified: (a) use of organizational routines based on reference to past experience, (b) season shared time management and, (c) time management based on flexible plans.

Use of Organizational Routines Based on Reference to Past Experience. Time management was based on experience over previous years. Coaches based routines linked to the repetition in the competition dates of the international and national calendars and the events experienced with athletes. An excerpt emphasizes the repetitions experienced by coaches:

"We are organized according to the international calendar. I know the important competitions; it always functions in the same way. We get this calendar each year; we choose the competitions to which we want to commit, according to the level of the players and our goals. Then we coordinate it with the national calendar".

This coach organized the season according to the dates of competitions that were broadly known from one year to the next. Another excerpt reveals that time management was based on the use of routines linked to the events experienced with athletes:

"We [the coaches] don't give athletes more than two weeks to go home, three weeks is too much. We know we can release some athletes for three weeks, they will continue to train. For some others that's three weeks to whoop it up, so we prefer to have everybody in the institute. It depends on the period too, we free athletes for Christmas. Many of them go home; we respect this need. It's the same in summer; we give them a little more time because they are saturated". 
This coach had learnt he could not organize each period of the year as he would have wanted to. He had to respect athletes' rhythms to keep them involved in the training process. His experience with some athletes led him to compromise between the necessity for athletes to go home and the tendency of some of them to stop training during this period. Some coaches could not release their athletes when they were in competition periods. They tried to but when there was a conflict between times to prepare for competitions and times to go home, they favored competitions instead of home rest. For example a coach said:

"during the Olympic year, the athletes whose families live in the West Indies can't go home, because the season is very dense. They haven't enough time to go home."

Time was managed with regard to the anticipated result; this coach tried to compromise between time to train and time to go home, but he stopped compromising when the compromise could prevent the anticipated result from being achieved.

Season Shared Time Management. Season time management was shared between coaches and athletes. It was based on: (a) discussions and agreements between the coaches about the work to do with athletes, (b) discussions and agreements between the coach and his athletes about the work to do and athletes' requests about their involvement in specific competitions, and (c) a comprehensive coaches' attitude. An excerpt emphasizes that time management was shared between the coaches:

"I plan first with the coaches, we go to one direction of work and we discuss it. Each of us investigates by himself and then we try to discuss it together. In staff meetings, some coaches don't talk very much. Some of them do what they want and it's not good. At a minimum, we have to agree on the direction of the work. If not, we discuss it in order to reach a consensus."

The organization was not always shared by all coaches, some of them preferred working alone and that could be a real problem for the staff. Another excerpt reveals the collaboration between the coach and his athletes:

"I set out the time span with him/her, because I've seen that it's very important to obtain the trust of the athlete by involving him/her. Some athletes have difficulty involving themselves during our discussions; they don't want to give their opinion. But I invite them to do so. We look over the content of the training program for each athlete, according to our particular aims. We decide on what sort of drills we're going to do and what sort of teaching aids and procedures we're going to use. We do this in order to obtain the athlete's commitment. After three or four weeks, we assess the period in order to determine whether to continue or change".

This coach emphasized the importance and sometimes the difficulty of getting his athletes to commit to organizing the training period. Their collaboration concerned the direction, content and duration of the work period. Time management was also based on a comprehensive attitude of the coaches toward the athletes. They wanted the athletes to commit to the training process to achieve the anticipated result. To 
do so, they tried to organize the training periods taking into account the athletes' individuality. An excerpt emphasizes this attitude:

"I give athletes a general program and then there are adjustments for the athletes who are married and have children. That's completely different from those who are single and live in the institute. I'm aware it's more difficult for them I know I have to organize this. Then, there is a negotiation; it's like an agreement regarding what they want and the goal. This year, an athlete would have liked to prepare for competition for two weeks and then go directly to the European Championships. We tried to negotiate. There was permanent conflict with the athlete and the athlete's club which considered we focused on the athlete too much. We have to be careful, we can discuss it but at a point we must agree on a minimum time frame: two tournaments with one month to prepare for all athletes. She obviously trains before, by herself, in her club and we assess this training."

In this excerpt, time was organized differently for different athletes: a general framework for single athletes and adapted framework for a few married athletes. This coach showed a comprehensive attitude toward the latter. He accepted their will to train near their family, he organized different time-frames for them and at the same time he did not lose sight of the anticipated result. He compromised until the trade off threatened to prevent the athlete achieving the anticipated result. Then, he stopped and imposed a minimum time-frame to prepare for competitions. His comprehensive attitude was counterbalanced by his will to achieve the anticipated result.

\section{Time Management Based on Flexible Plans.}

To organize the season or shorter work periods, coaches set plans to give the work a framework. The coaches were prepared to adjust their plans to take into account the uncertainty linked to the evolution of training and the availability of facilities. Their plans appeared to be flexible. Flexibility depended on the time-span preceding the competition. For example, a coach said:

"In May and June, we're in both a competition cycle and an academic exam period. We have to juggle sport and studies. We have a written time-frame, but we can't have rigid organization. In this period, we listen to athletes, and as soon as the athlete has an unusually painful sprain, we break and delete the session the day after. At this period we have to pay attention to the athletes who listen too much to themselves. In November, we carry out the planned sessions of two weeks. If a problem appears, I say to them: you do the session, you run less fast but you finish it."

The coach adjusted the plan for the athlete's progression differently in this period. In one case, because of the dynamic and uncertain nature of the setting and the proximity of the competition, the plan was more flexible. In the other case, he generally did what was planned. Coaches kept in mind a framework and adjusted it according to the events which occurred. 


\section{Discussion}

The results of the current study showed how coaches managed time to allow an anticipated result to be achieved. Coaches dealt with a stringent set of constraints and used complex operating modes. This aim of accommodating constraints led coaches to compromise. The findings will be discussed from three perspectives: time management and planning process, compromises aimed at achievement in the context of constraints and implications for practice.

\section{Time Management and Planning Process}

As was found in the planning topic (Jones et al., 1995; Platonov, 1988; Weineck, 1996) and goal setting perspective (e.g., Horton \& Deakin, 2008; Burton \& Raedeke, 2008; Burton \& Weiss, 2008), planning was based on a vision of the future (i.e., an anticipated result in a competition or a level reached at the end of a specific time frame). It consisted of the steps and time frames that coaches thought were required to reach the goal. Côté and Sedwigck (2003) showed that planning was proactive. However the present results suggested that planning was also retroactive. Coaches planned regarding an anticipated result that was considered as a fixed point. From this fixed point, they looked at the 'past' (which was not realized yet) and organized the season and its time-frames for: (a) competitions, (b) training camps, (c) athletes' out-of-training activities, and (d) athletes going home. To organize these time-frames, they took into account athletes' and federation requests and available funding. Then they sequenced training periods and tasks, and fitted into the institute's set training times. During the season, they adjusted the training periods according to the uncertainty linked to the evolution of training. This adjustment related to proactive planning which consisted of fitting the anticipated result to the real events to generate an outcome. This proactive planning was followed by the retroactive planning process described earlier to adjust training period sequencing. The use of the retroactive and proactive processes is consistent with Dupuy's (2002, 2008) model. Coaches' actions were based on different mixed temporalities that referred to: (a) past experiences with athletes and the redundancy of the competition calendars, (b) current situations, and (c) the anticipated result. The present results reinforced those shown by Saury and Durand (1998) and Sève and Durand (1999) on coaches' activities during short time-frames (i.e., a session), and extended them to longer time-frames (i.e., a season). The present results, therefore provide new insight into how coaches in elite sport settings manage and organize time over the course of a sport season.

As was found in the coaches' knowledge topic (Côté, 2006; Côté \& Gilbert, 2009; Abraham et al., 2006; Gilbert \& Trudel, 1999, 2005), coaches used professional, interpersonal and intrapersonal knowledge to manage time. Knowledge concerned constraints and was employed in cognitive activity. Professional knowledge involved the constraints imposed upon the coaches when managing time. Some of these constraints were related to the institute in which the sports practice took place; they included the imposed sports training schedules and availability of facilities. These contextual constraints were little reported in previous studies although they are important in countries such as the U.S.A, Germany and France, 
where the athletes are committed in both sports and academic programs within sports institutes and universities (e.g., Bouchetal-Pellegri et al., 2006). As shown by Dubar (2004) in sociology, coaches appropriated the institute-imposed schedules to construct group and individualized times governed by the achievement of the anticipated result. Interpersonal knowledge was concerned with the uncertainty linked to the evolution of training (except changes in the availability of facilities) and the season shared time management (except the comprehensive attitude). Intrapersonal knowledge referred to: (a) the use of organizational routines based on reference to past experience, (b) the comprehensive attitude, and (c) the time management based on flexible plans.

Time was managed with regard to sports, athletes' out-of-training activities and athletes going home. These results suggested that the role of the coach consisted of sport and personal development of athletes, consistent with the results of previous coaching research that emphasized the need to adopt a holistic view of training (Côté, 2006; Côté et al., 1995; Côté \& Sedwigck, 2003; Salmela, 1996; Gilbert \& Trudel, 2000; Gould et al., 2002; Wylleman \& Lavallee, 2004). Results suggested that times were fragmented and multiple. They were concerned with different athletes' involvement. For example, one coach stressed a specific time fragmentation regarding the locus of training. In training camps, time was organized solely around sports training, while in the institute time was organized around sports training and out-of-training activities. This time fragmentation is consistent with the temporal systems described elsewhere in the literature (Audigier, 2007; Dubar, 2004; Francis-Smythe \& Robertson,1999; Grossin, 1996; Sabelis, 2001; Southerton, 2003). These authors showed that managers' time was divided up by their activities into different time-frames (e.g., meetings, meals). These time-frames succeeded one another, juxtaposed, competed and led managers to adjust them. To avoid or limit conflicts between athletes' times, coaches took into account this time fragmentation. Coaches organized athletes' sports times by giving athlete times for out-of training activities and also time to go home. Sport training theories (e.g., Weineck, 1986) consider that rest is a part of training. However the present results showed that another form of rest was important for athletes: they needed to go home for short periods to avoid burnout. As suggested by Horton and Deakin (2008), this structure aimed to prevent loss of valuable time due to overuse injuries, staleness or burnout.

\section{Compromises Aimed at Achievement in a Context of Constraints}

The results showed that coaches compromised on constraints to manage athletes' time to achieve the anticipated result. Compromise activity comprised a continual transformation of the problem with regard to conflicts between constraints (Jeannot, 2005). For example a coach had to deal with time to prepare for competition in the institute and the desire of some married athletes to train near their family. He had to generate a new time organization that was negotiated while keeping the anticipated result in sight. Time management could be considered to be a confrontation between contradictory elements. Compromises resulted from this confrontation. Compromises were made until they prevented the athletes from achieving the anticipated result. The present results reinforced those shown by Jeannot (2005) in 
his study on project managers. They also reinforced the role of goal prioritization and coordination explained by Burton and Raedeke (2008) in sport psychology.

Results showed shared time management between athletes and coaches. Discussions with athletes and coaches through a comprehensive attitude aimed to take into account their focus about the work to be done with athletes. Results suggested that these discussions permitted coaches: (a) to create and maintain a positive training environment, (b) to help athletes to define and adjust their goals, and (c) to build athletes' confidence. The present results reinforced those obtained by Côté and Gilbert (2003, 2009), Gould et al. (2002), and Horton and Deakin (2008) on coaches' effective behaviors. They also emphasized the shared work organization that, to our knowledge has only been shown by Saury and Durand (1998) in time organization.

Compromises consisted of individual inventiveness to achieve the anticipated result and to accommodate constraints. For example, a coach adjusted training to the available space by dividing time with a group and playing in or out of the court. These individual inventions based on compromises are consistent with those presented by Duc (1993). The organization of work requires individual inventiveness to manage uncertain realities of events. The work was not totally prescribed, such as is the definition of work organization. The coaches did not deal with well-structured problems (Reitman, 1965) where the data required would be sufficient and available. Rather they dealt with uncertainty and changes; they carried out actions according to the way they interpreted the situation. The present results reinforced those shown by Langa (1997) and Carballeda (1997), in their studies about managers' work. Coaches used flexible plans to adjust what was planned to what could be carried out, to achieve the anticipated result. Plans appeared to be more flexible, when the competition was near than when it was distant. Theories of planning consider that coaches have to carry out what is planned (e.g., Platonov, 1988; Weineck, 1986). However the present results and those of Saury and Durand (1998) and Sève and Durand (1999) showed that plans were flexible. They were used as a frame work and proceeded step-by-step, being dependent on-going events. With a stringent set of constraints, coaches did not try to maximize time, as suggested by Horton and Deakin (2008). Rather, they tried to optimize it in compromising between the requirements and the on-going events.

\section{Implications for Coaching and Coaching Education}

These results suggest some implications for less experienced coaches. The coaches could continue to manage time over the season according to professional knowledge (Côté, 2006; Côté \& Gilbert, 2009). At the same time, they could take into account their athletes' activities beyond sports training, the practice conditions in the training center (which may also be an academic training institute) and the on-going events. A specific framework could be developed containing questions about: (a) the types of constraints linked to time management and with regard to the specificity of each sport (e.g., competition calendar) and training context (Côté \& Gilbert, 2009) including the institute's set times, and the implications of the constraints for the coaches, (b) the strategies that can be used and the compromises that have to be made which are dependent upon the way coaches interpret situations to manage athletes' time, (c) the outcomes of their retroactive (Dupuy, 2002, 2008) and proactive (Côté \& 
Sedgwick, 2003) planning with regards to the compromises made and the need to use flexible plans, and (d) the existence of intermixed temporalities (Saury \& Durand, 1998; Sève \& Durand, 1999). This framework could be used to learn how to manage time with a stringent set of constraints. It could allow coaches to stand back from their work by leading them to consider: (a) what they can or cannot do to achieve the anticipated result while taking into account the constraints they consider important, (b) where they compromise without preventing the anticipated result from being achieved, and (c) how they can manage new constraints. The framework could allow coaches to be considered as learner and manager at the same time. They could learn from the context, their own experience, and discussions with colleagues about their time management experience (present results). To achieve the anticipated result, they would have to redefine the problem in the light of the constraints which arise (Jeannot, 2005) and the constraints' importance for coaches. They would need to develop new time organizations to fit uncertain realities of events (Duc, 1993) and use organizational modes that were efficient in the past (Saury \& Durand, 1998). Uncertainty linked to the evolution of training means that coaches manage time by proceeding step-by-step and taking on-going events into account (Saury \& Durand, 1998).

\section{Conclusion}

It seems inappropriate to generalize from a qualitative study of ten coaches. Despite this limitation, this article addresses an issue in relation to the research on coaching and time management by providing a framework that accounts for the process, the knowledge and the strategies used by male coaches of elite athletes when they managed time to prepare athletes for competitions during a season. It emphasizes that coaches: (a) dealt with uncertainty and change, carried out actions according to the way they interpreted the situations, (b) made compromises to achieve the anticipated result in a context of stringent constraints, and (c) used a retroactive and proactive planning activity including flexible plans to adjust what had been planned to what could be carried out, to achieve the anticipated result. This leads to the adoption of a holistic view of training and consideration of time management as a chaotic activity governed by the accomplishment of an anticipated result in a stringent set of dynamic constraints. The challenge remaining will be to discover how time is managed in different sporting contexts and by coaches of varying profiles (e.g., gender, years of experience, expertise).

\section{Acknowledgments}

This study was supported by a grant from the French Ministry of Health and Sports. The author is grateful to the coaches for their participation to this study, to Nadine Debois for her participation in the data processing and to the reviewers for their helpful comments during the reviewing process. 


\section{References}

Abraham, A., \& Collins, D. (1998). Examining and extending research in coach development. Quest, 50, 59-79.

Abraham, A., Collins, D., \& Martindale, R. (2006). The coaching schematic: Validation through expert coach consensus. Journal of Sports Sciences, 24(6), 549-564.

Audigier, F. (2007). Temps subis, temps construits [Constructive times from inflictive times]. In D. Lahanier-Reuter, \& E. Roditi (Eds.), Questions de temporalité (pp. 15-27). Villeneuve d'Asq: Presses Universitaires du Septentrion.

Bouchetal-Pellegri, F., Leseur, V., \& Debois, N. (2006). Carrière sportive. Paris: INSEPPublications. [Sporting carreer].

Bowes, I., \& Jones, R.L. (2006). Working at the edge of chaos: Understanding coaching as a complex, interpersonal system. The Sport Psychologist, 20, 235-245.

Burton, D., \& Raedeke, T.D. (2008). Sport psychology for coaches. Champaign, Il: Human Kinetics.

Burton, D., \& Weiss, C. (2008). The fundamental goal concept: The path to process and performance success. In T. S. Horn (Ed.), Advances in sport psychology (pp. 339-375). Champaign, Il: Human Kinetics.

Carballeda, G. (1997). Les cadres: des travailleurs en difficulté [Managers: workers in difficulty]. Performances Humaines et Techniques, 91, 11-15.

Corbin, J., \& Strauss, A. (1990). Basics of qualitative research: Grounded theory. Procedures and techniques. Newbury Park, CA: Sage.

Côté, J. (2006). The development of coaching knowledge. International Journal of Sports Science \& Coaching, 1(3), 217-222.

Côté, J., \& Gilbert, W. (2009). An integrative definition of coaching effectiveness and expertise. International Journal of Sports Science \& Coaching, 4(3), 307-323.

Côté, J., Salmela, J. H., Trudel, P., Baria, A., \& Russel. (1995). The coaching model: A grounded assessment of expert gymnastic coaches' knowledge. Journal of Sport \& Exercise Psychology, 17(1), 1-17.

Côté, J., \& Sedgwick, W.A. (2003). Effective behaviours of expert rowing coaches: A qualitative investigation of Canadian athletes and coaches. International Sports Journal, $7(1), 62-77$.

Cushion, C.J., Armour, K.M., \& Jones, R.L. (2003). Coach education and continuing professional development: Experience and learning to coach. Quest, 55, 215-230.

Dubar, C. (2004). Régimes de temporalités et mutation des temps sociaux [time systems and social time change]. Temporalités, 1, 100-119.

Dubar, C., \& Tripier, P. (2005). Sociologie des professions. Paris: Armand Colin. [Sociology of the professions].

Duc, M. (1993). Le travail en chantier. Toulouse: Octarès. [The work in hand].

Dupuy, J-P. (2002). Pour un catastrophisme éclairé. Paris: Seuil. [Towards an enlightened view of Catastrophe].

Dupuy, J-P. (Ed.). (2008). Dans l'oeil du cyclone. Paris: Carnets Nord. [In the eye of Hurricane].

Francis-Smythe, J., \& Roberston, I. (1999). Time-related individual differences. Time \& Society, 8(2), 273-292.

Gilbert, P., \& Trudel, W.D. (1999). Framing the construction of coaching knowledge in experiential learning theory. Sociology of Sport On-Line, 2(1) Available at: http:// physed.otago.ac.nz/sosol/v2i1/v2i1s2.htm.

Gilbert, W., \& Trudel, P. (2000). Validation of the Coaching Model (CM) in a team sport context. International Sports Journal, 4(2), 120-128.

Gilbert, P., \& Trudel, W.D. (2005). Learning to coach through experience: Conditions that influence reflection. Physical Educator, 62, 32-43. 
Gould, D., Guinan, D., Greenleaf, C., \& Chung, Y. (2002). A survey of U.S. Olympic coaches: Variables perceived to have influenced athlete performances and coach effectiveness. The Sport Psychologist, 16, 229-250.

Grossin, W. (1996). Pour une science des temps: Introduction à l'écologie temporelle. Toulouse: Octarès. [For a science of times: Introduction to a temporal ecology].

Horton, S., \& Deakin, J.M. (2008). Expert coaches in action. In D. Farrow, J. Backer, \& C. MacMahon (Eds.), Developing sport expertise (pp. 75-88). London \& New-York: Taylor and Francis.

Jeannot, G. (2000). Faire du général avec du singulier: Les chefs de service d'une DDE et l'aménagement [Making general from singular: heads of the regional Amenities department and development]. Les annales de la Recherche Urbaine, 88, 49-57.

Jeannot, G. (2005). Les métiers flous. Toulouse: Octarès. [The vague jobs].

Jones, R.L. (2000). Toward a sociology of coaching. In R. L., Jones, \& K. M. Armour (Eds.), Sociology of sport theory and practice (pp.33-43). London: Addison Wesley Longman.

Jones, D.F., Housner, L.D., \& Kornspan, A.S. (1995). A comparative analysis of expert and novice basketball coaches' practice planning. Applied Research in Coaching and Athletics Annual, 10, 201-227.

Jones, R.L., \& Wallace, M. (2005). Another bad day at the training ground: Coping with ambiguity in the coaching context. Sport Education and Society, 10(1), 119-134.

Lamberbourg, A., \& Paudardin, M. (2008). Enquête nationale sur les conseillers techniques sportifs féminins [A survey of French female managers and coaches]. In G. Quintillan (2008) (Ed.) Le sport de haut niveau au féminin, pp. 225-233. Paris: Editions INSEP.

Langa, P. (1997). L'activité des cadres: un objet d'étude [Managers' activity: a study object]. Performance Humaines \& Techniques, 91, 25-30.

Platonov, V.N. (1988). L'entraînement sportif. Théorie et méthodologie. Paris: INSEP Editions. [Sport training. Theory and methodology].

Potrac, P., Brewer, C., Jones, R., Armour, K., \& Hoff, J. (2000). Toward an holistic understanding of the coaching process. Quest, 52, 186-199.

Potrac, P., \& Jones, R.L. (1999). The invisible ingredient in coaching knowledge: A case for recognising and researching the social component. Sociology of Sport On-Line, 2(1) Available at: http://physed.otago.ac.nz/sosol/v2i1/v2i1a5.htm.

Reitman, W. (1965). Cognition and thought. New York: Wiley.

Sabelis, I. (2001). Time management: Paradoxes and patterns. Time \& Society, 10(2-3), 387-400.

Salmela, J.H. (1996). Great job coach! Getting the edge from proven winners. Ottawa: Potentium.

Saury, J., \& Durand, M. (1998). Practical knowledge in expert coaches: On-site study of coaching in sailing. Research Quarterly for Exercise and Sport, 69(3), 254-266.

Sève, C., \& Durand, M. (1999). L'action de l'entraîneur de tennis de table comme action située [Action of table tennis coach as situated action]. Avante, 5(1), 69-85

Southerton, D. (2003). 'Squeezing time'. Alocating practices, coordinating networks and scheduling society. Time \& Society, 12(1), 5-25.

Weineck, J. (1986). Manuel d'entraînement. Paris: Vigot. [Optimal training].

Wylleman, P., \& Lavalle, D. (2004). A developmental perspective on transitions faced by athletes. In M. R. Weiss (Ed.), Developmental sport and exercise psychology: A lifespan perspective (pp. 503-523). Morgantown, WV: Fitness Information Technology. 